\title{
Reflections on Improving Humanistic Quality Education of Senior High School Students
}

\author{
Changhai Tian \\ Northeast Normal University Affiliated High School; 130021, China
}

414017587@qq.com

Keywords: Senior high school student, Humanistic quality, Humanistic spirit.

\begin{abstract}
On the basis of studying the connotation of humanistic spirit and the present situation of humanistic quality of senior high school students, this paper proposes to improve the current situation of humane quality education of senior high school students from three aspects. These three suggestions include improving the personality charm of teachers, building a scientific extracurricular reading system and building a campus culture with a strong humanistic flavor.
\end{abstract}

\section{Introduction}

In the course of middle school education, quality education is an indispensable topic. The content of middle school education can be divided into scientific education and humanistic education, and the two are two different aspects of the all-round development of human beings. The development of science education focuses on wisdom, reason and ability, through the "truth", make its behavior conform to objective law; the formation and establishment of humanistic education focused on social values, norms, emotion, through "goodness", which meets the reality of behavior. An all-round development of people, not only need to have a scientific education which has rational method, at the same time, they need more humanistic literacy consists of its comprehensive knowledge structure, and thus create a complete personality and perfect mode of thinking. The high school stage is the third stage of student learning not only carries the education of students and improves students' comprehensive ability; there is a very important task that is to have in life form an important period of senior high school students, humanistic education is necessary. Neglecting the education of humanistic quality will inevitably affect the all-round development of individuals.

\section{Connotation of Humanistic Quality}

The term "humanism" first appeared in the book of changes, which has the meaning of nurturance, cultivation and standardization of human behavior. In western education, the humanistic spirit springs from the wisdom and Socrates of ancient Greece and advocates the humanistic spirit of equality. Humanistic accomplishment is the basic ability, emotion, attitude and value orientation of students in learning, understanding and using the knowledge and skills in the humanities field. It includes the basic points of human culture, humanistic feelings and aesthetic taste. The key point of humanistic accumulation is the accumulation of the basic knowledge and achievements in the human world at all times and in all lands, and can understand and grasp the cognitive methods and practice methods contained in the humanistic thought. The humanistic feeling focuses on the consciousness of being human centered, respecting and maintaining human dignity and value, and concerned about the survival, development and happiness of human beings. The key is to have an art aesthetic knowledge, skills and methods of accumulation; to understand and respect the diversity of culture and arts, has found, perception, appreciation and evaluation of beauty consciousness and ability; aesthetic value orientation of health; artistic expression and creative expression of interest and awareness, to expand in life and sublimation beauty. 


\section{Problems Existing In Humanistic Quality Education of Senior High School Students}

High school students receive strong, extensive knowledge, strong self-consciousness and independent personality, but the humanistic quality is worrying, such as native culture due to the rapid development of the network's fast food culture, more and more lacking of traditional culture heritage, in the written expression of daily basic Chinese syntax is not standardized in interpersonal communication; speaking, to deal with poor, lack of logic, his weak phenomenon is prominent; literature, history and philosophy of knowledge; individualism serious deviation, the emergence of these problems and the humanities education has the very big relations with the lack of.

\subsection{Focus on the "Utilitarian" of Knowledge and the Lack of Humanistic Education}

In the background of exam oriented education, high school classroom is mostly in the positive test, pro forma; knowledge is also basically the examination service, such as in language learning, teachers from the word and sentence, and discourse to implement one by one. Focus on the analysis of words and memory, sentence changes, reading comprehension skills, writing scores and tips and other aspects of the professor. Focus on problem-solving skills summary and explanation, will learn the knowledge as a tool to obtain the high score, this utilitarian knowledge will greatly reduce the learning interest of the students, reduce their exploration in future and unknown and desire for knowledge and neglect humanities education, neglect of students' subjective humanistic spirit self-training guide.

\subsection{Humanities Education, Exaggeration and Walk Through The Field}

Another situation is contrary to the lack of humanistic education, humanistic education is virtual, exaggerated, and do some of the humanities education in the classroom, such as focusing on the introduction of some famous celebrity gossip and private life, explore some privacy issues. Or to hold temporary activities, it is not enough to achieve humanistic education through these short activities. Humanities education itself is a continuous process, need teachers teach, to subtle influence and guidance of students, is by no means through some gossip about the secret, through a brief activity can achieve.

\subsection{Text Reading Teaching Ignores the Humanistic Education Guidance}

There are three kinds of "anti-humanity" teaching phenomena in the current text reading teaching: The first is the fast reading, the reading of students is overwhelming, but it is far from classical reading. Students are mostly reading light reading, reading books are mostly pocket books, abbreviations, drawing books and e-books based. They do not have their spiritual home; they are separated from traditional culture and traditional spirit. Next is the pattern of reading. The students' practice of the use of text language, machinery, always feel that the way is narrow, the reading model is rigid, the interpretation of the article is unrealistic, into the teaching of reading program. Finally, reading is utilitarian. Students' appreciation and evaluation of texts are more utilitarian and superficial. It reflects that in text interpretation, they are simply "learning to use", and "moving" immediately". Students cannot comprehend the cultural background hidden behind the text. They cannot understand the article from the angle of cultural recognition, and feel the real life.

\section{Suggestions on Improving Humanistic Quality Education of Senior High School Students}

If you follow the "checklist" your paper will conform to the requirements of the publisher and facilitate a problem-free publication process.

\subsection{Enhance Teacher's Personality Charm}

As a teacher, the values of the social and cultural values reflected by the personality of teachers are reflected in the values of social culture. It is an important reference for students' humanistic quality construction. If teachers have abundant professional knowledge without humanistic spirit, it is impossible to talk about the cultivation of students' humanistic quality. The profound knowledge, the rich experience and the high interest of the teacher, the affection, kindness, trust and tolerance of the students can have the influence on the cultivation of the students' humanistic quality. As a middle school teacher, in the face in an eager, but being active and energetic in the outlook on life and values 
and has yet to finalize the design students, should be fair and objective, generous and philanthropic heart to guide, care, understanding, respect, care for each student. Teachers should tolerate students with different temperament and interests. Students who perform well, perform well, or perform poorly, should be treated equally. To communicate with love and understanding students' mind, enlighten students' intelligence, strengthen students' self-esteem and self-confidence, so that they can find their own value, with optimistic attitude to face the life and learning, forming and perfecting the independent personality.

\subsection{Build an Extracurricular Reading System}

Through the construction of extracurricular reading physical energy, enrich and improve the humanistic spirit material. Teaching should pay attention to class teaching in high school at the same time, the focus of establishment and improvement of the extracurricular reading system, such as Chinese textbook is the literary works in the education experts and scholars carefully select and compile and selection of classic literary works, but by the content of the textbook, only limited classroom teaching time, not effective enough to foster high literary accomplishment and spirit, edify students' sentiment. Teachers should make full use of modern multimedia technology, make rational use of rich network resources, and constantly improve humanistic spirit material.

First of all, teachers can recommend excellent literary works for students. After the students have finished reading, they can organize communication and discussion, and share with them the thoughts and questions after reading. To cultivate students' good habits of thinking and accumulation, and to improve students' aesthetic ability and appreciation ability, promote the infiltration of humanistic spirit and improve students' humanistic quality. At the same time, for the third year is about to face the university entrance exam students, teachers should recommend some self-help books more, inspire learning, struggle of passion, encouraging its sets up the lofty aspirations and goals, for learning, and move on.

\subsection{Build a Deep Campus Humanistic Environment}

Build middle thick campus cultural environment, build a school culture characteristics of campus culture, to develop the historical and cultural resources of the school, the concise for the school's educational philosophy to guide and motivate students, make students improve the humanities cultivated manners in the culture of the life-giving edify. With more typical outstanding graduates of free-standing self-improvement, sensible, credible set an example among the students, let students understand and know their value orientation, motivate them with reason to guide their own thoughts and behavior, set up the correct outlook on life and values; Through the construction of the class wind and study style, the humanistic education is embodied, and the classroom becomes the position of students to express themselves and optimize their individuality. At the same time, the school motto is a school educational philosophy and the reflection of the school spirit, is the concentrated reflection, teaching and learning, school spirit, strengthen the school motto of formulation and propaganda, let the school spirit deeply in the heart of the middle school students.

\subsection{Implement Humanistic Evaluation}

The main purpose of teaching evaluation is to realize the students thought more comprehensive knowledge and understanding, but also an important way to reflect on the teaching methods of teachers, teachers of students evaluation of a variety of ways, but the differences between different students, teachers should respect the differences between the students, pay attention to the psychological change of senior high school students and different psychological activities, so as to reflect the principle of individualized. Humanistic evaluation is the first of all the humanistic rules of the evaluation of teachers. In the evaluation, teachers should pay attention to the respect of the words in the evaluation. The wording of the teachers in the evaluation of use must be more not only realized the respect for the students, but also achieved to mobilize students' learning interest and enthusiasm, make the other students are also willing to actively to answer the question. Teachers have to look with a view of the students, good at find the best in students, for students to answer or bad performance in the classroom; teachers can be tactful language or subtle movements to remind students. 


\section{Conclusion}

Humanistic education can not only improve the relevant knowledge level, but also combine human's excellent ideological and cultural achievements to influence a person, thus improving the quality and quality of people. Teachers in the teaching process, therefore, must pay attention to human resources fully, at the same time of spreading knowledge, more should strengthen the students cultivate the spirit of humanity, to help students build up confidence, firm faith, and learn to insights gained from learning and make their own personality in learning.

\section{References}

[1]. Lin Qihong. College culture immersion: a new path for high school students' humanistic quality cultivation. Shanghai education scientific research. Vol. 29 (2013) No. 8, p. 76-77.

[2]. Han Jing. Study on the penetration of humanistic spirit education in high school biology teaching and research. Vol. 226 (2015) No. 12, p. 86.

[3]. Jin Bin. On the guiding strategy of high school literature humanistic feelings. Journal of Xiamen radio and Television University. Vol. 29 (2012) No. 3, p. 79-83.

[4]. Yungui Wang,Yanxia Jiang. Investigation and research on the cultural background of primary and middle school students in Shandong province. Vol. 69 (2017) No. 3, p. 37-40. 